Vol.15, No. 57, October, 2020, 953-962

\title{
ENHANCEMENT OF CONCRETE PROPERTIES AND STRUCTURAL SYSTEM FOR TELECOMMUNICATION MANHOLE COVERS
}

\author{
Waleed Helal*, Fareed Elgabbas, and Yehia Abdel Zaher \\ Structural Engineering Department, Faculty of Engineering, Ain Shams University, \\ Cairo, Egypt. \\ *Corresponding Author E-mail: Waleed.Helal@yahoo.com
}

\begin{abstract}
:
This study aims to enhance the concrete properties and the structural system of the cover of Telecommunications (T.E.) manhole covers in order to improve its abrasion resistance, increase safety factors, enhance the composite action, increase the load carrying capacity and lessen the potential risks. Through this study, different improvement materials were added to the concrete mixtures to enhance the mechanical properties of concrete, such as, compression, flexure, and abrasion resistance. Moreover, shear connectors were used in the steel concrete composite covers to evaluate their structural performances under centrally applied localized loading. It was concluded that producing concrete by adding $10 \%$ silica fume of cement content and $50 \mathrm{~kg}$ of steel fibers per cubic meter, increased the abrasion resistance of the modified concrete by $48 \%$ compared to the designed mix. Moreover, the maximum load bearing capacity for the developed covers with the enhanced concrete and shear connectors increased by $31 \%$ compared to the commercial covers with normal strength concrete and bottom steel bars mesh. The commercial covers bearing capacity is lower than the permissible bearing capacity of $250 \mathrm{kN}$ according to BS EN 124 for covers class C250. While developed covers comply with BS EN 124 for the Covers class C250. Therefore, both of the shear connectors and the enhanced concrete have a significant effect on the bearing capacity that make the covers able to be installed safely in the area of curbside of roads.
\end{abstract} KEYWORDS: Manhole Covers, High Strength, Silica Fume, Steel Fibers, and Shear
Connectors.

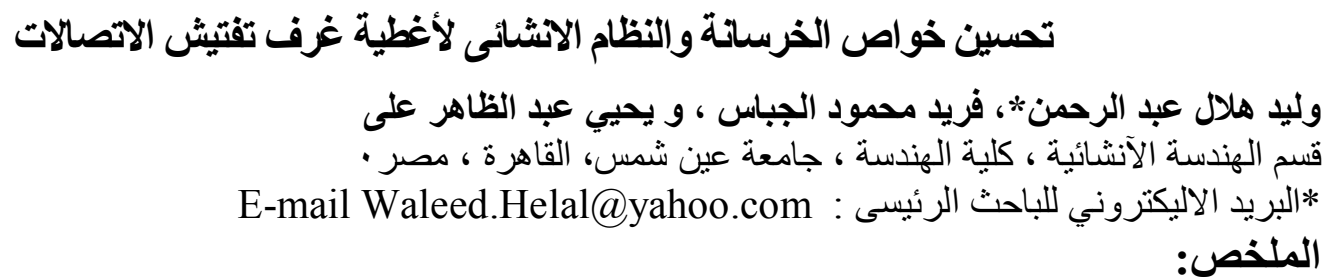

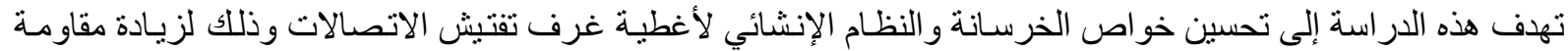

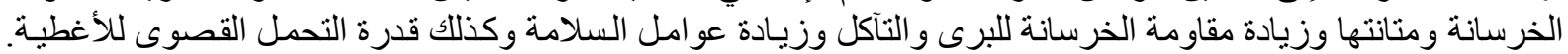

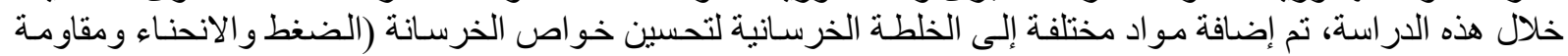

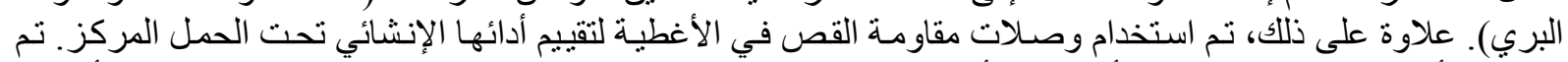

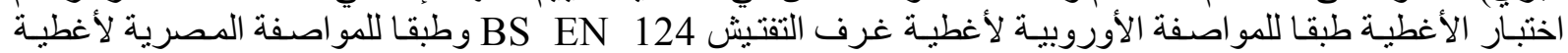

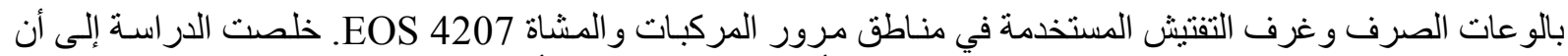

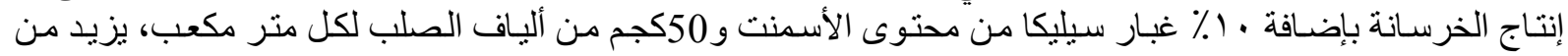




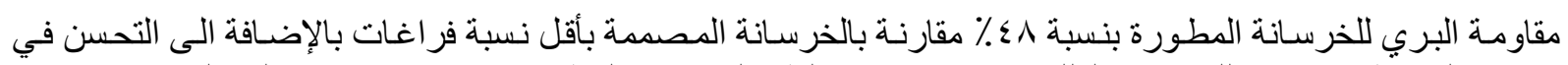

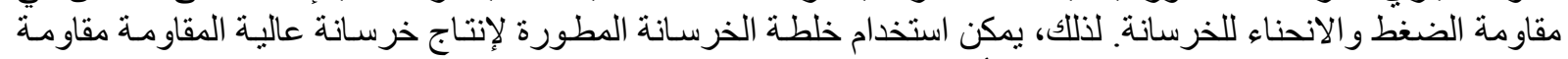

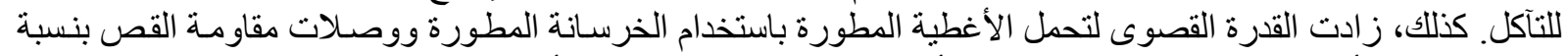

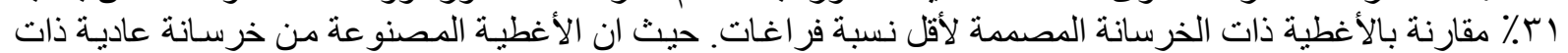

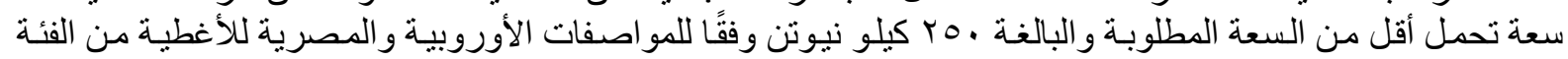

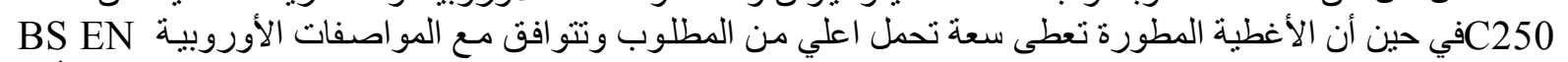

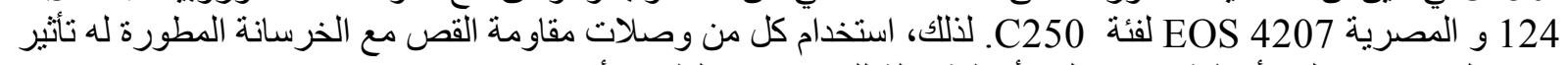
كبير على قدرة تحمل الأغطية مما يجعل الأغطية قابلة للتركيب في الطرق بأمان تام.

الكلمات المفتاحية : أغطية غرف التفتيش، عالية الإجهاد، غبار السيليكا، الياف الفولاز، وصلات القص.

\section{INTRODUCTION}

Most of the telecommunications (TE) manhole covers that are being currently used in Egypt and Middle East are manufactured using a normal strength concrete embedded in a steel frame as shown in Fig. 1. The main advantage of those manhole covers is the low cost in comparison to the cast iron covers. Moreover, A common problem associated with cast iron manhole covers is the theft of the cover and then selling it on the black market (El Haggar and El Hatow, 2009). Also, the most common problem that is associated with the current concrete TE manhole concrete covers is the deterioration of concrete and collapsed covers that result in large holes all over the roads causing many potential safety hazards and jeopardizing peoples' lives. Consequently, most drivers try to avoid pass-over the covers to avoid accidents.

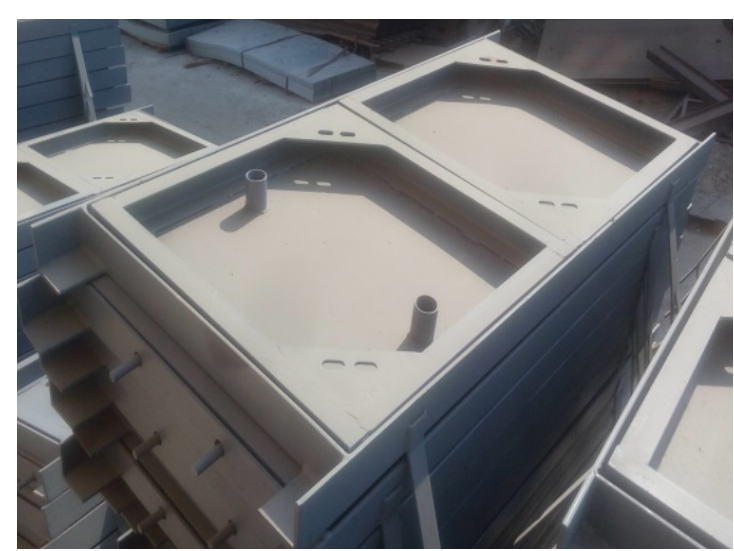

a) Steel frame (before concrete casting)
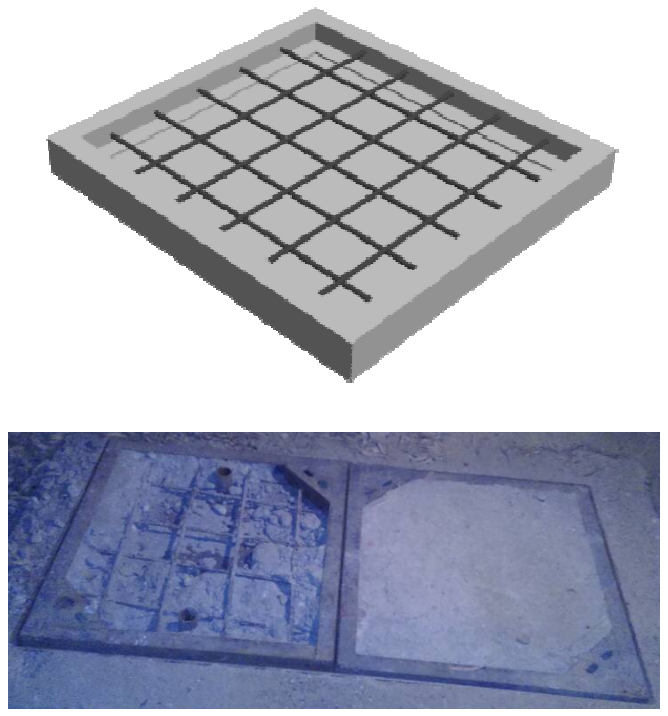

b) cover reinforcing bars

Fig. 1: Commercial TE manhole covers

The concrete TE manholes cover suffer from a short lifetime due to its lower concrete abrasion resistance, and insufficient bearing capacity which is not accommodated with the different intensity and loads of traffic. Therefore, its cost increased significantly due to the frequent replacement of covers. According to Egypt's primary telecommunication company (Telecom Egypt, 2019) survey the demand for TE manholes covers increased by $125 \%$ and the cost increased by $175 \%$ during the period from 2017 to 2018 , which led to a significant increase in the annual cost for covers. Moreover, it causes many safety hazards and risks for humans and vehicles. Therefore, enhancing the concrete properties and the cover structure will reinforce the short- and long-term performance, consequently, decrease the rehabilitation and replacement cost. This study investigates the newly developed concrete mixes and cover structure to produce covers with sufficient bearing capacity, abrasion resistance Moreover, 
steel fibers were used to enhance the abrasion resistance. Steel fibers significantly increase the toughness or post-cracking energy absorption characteristics, eliminate the brittleness of concrete and bridge the cracks

of concrete and resist their propagation (Nili and Afroughsabet, 2012).Those additives were used to improve both of physical and mechanical properties of concrete. The fresh and hardened concrete properties were investigated by slump, compression, flexure (4-point load) and abrasion tests.

Nevertheless, the commercial covers bottom steel mesh embedded within the concrete serves no structural function because steel concrete open sandwich construction replaces the steel bars mesh by a steel plate and the steel plate is more efficient in carrying biaxial stresses than a mesh of steel bars. In addition, the steel plate serves as formwork supporting the construction and fresh concrete loads and represents a safety element in case of concrete core collapse. This paper aimed to develop the structural system of the cover along with the enhanced concrete. In order to enhance the composite action and increase the load carrying capacity of the covers shear connectors were used in the steel-concrete (SC) open sandwich covers. A test program for covers specimens is carried out to evaluate their structural performances under centrally applied localized loading. This experimental program investigates the influences of shear connectors and material parameters on the bearing capacity of the SC open sandwich covers. The ultimate resistances, failure modes, load deflection behaviors, are presented and discussed.

\section{RESEARCH PROJECT}

This research project aims to enhance the TE steel-concrete (SC) composite manhole covers through two phases described as follows:

2.1. Phase (I) includes enhancing the physical and mechanical properties of concrete (concrete mix design) and therefore improve the abrasion resistance of the covers. The enhancement in the physical and mechanical properties in this stage was investigated and evaluated through several tests such as slump, compression, flexure (4-point load), abrasion tests to come out with a full conclusion of the additives effect on the abrasion resistance of the concrete.

2.2. Phase (II) includes developing of the structural system of the cover. In this phase TE cover with shear connectors instead of the steel mesh and with the enhanced concrete from Phase (I) was tested according to BS EN 124 "European standards for gully tops and manhole tops for vehicular and pedestrian users" (BS EN 124-1, 2015) and the standard no. 4207/2008 from "the Egyptian Organization for Standardization \& Quality" (EOS 4207, 2008). In this phase the experimental program focused on the ultimate strength behavior of the SC composite cover under patch loads

\section{MATERIAL PROPERTIES}

All experimental materials were selected from the local market, as they are commonly used, widely spread and easy to be obtained. The experimental materials are as follows:

Concrete: Two types of concrete mixture were used. The first mixture M0-S0-F0 simulates the commercial concrete mix that is used in the manufacturer of manhole covers. The cubic meter of this concrete mixture consists of $350 \mathrm{~kg}$ of ordinary Portland cement, $560 \mathrm{~kg}$ of sand, and $1280 \mathrm{~kg}$ of coarse aggregate with a water/cement ratio (w/c) of $68 \%$. While the second concrete mixture M1-S0-F0 was designed to have minimum voids ratio. The cubic meter consists of $350 \mathrm{~kg}$ of ordinary Portland cement, $768 \mathrm{~kg}$ of sand, and $1105 \mathrm{~kg}$ of coarse aggregate with a water/cement ratio of $50 \%$. Crushed clean dolomite of $12 \mathrm{~mm}$ maximum size and 2.69 specific gravity was used as coarse aggregate. Natural available clean sand having size smaller than $5 \mathrm{~mm}$ and having 2.66 specific gravity was used as fine aggregate. The sieve analysis of coarse aggregates is shown in Table 1. The physical properties of aggregates are given in Table 2. 
Table 1: Sieve Analysis of Course Aggregates

\begin{tabular}{rrrrrrrr}
\hline Opening Size (mm) & 37.5 & 31.5 & 28 & 20 & 10 & 5 & pan \\
\hline Passing (\%) & 100 & 100 & 100 & 100 & 74.7 & 2.3 & 0 \\
\hline
\end{tabular}

Table 2: Physical Properties of Aggregates

\begin{tabular}{ccc}
\hline Property & Sand & Dolomite \\
\hline Volumetric weight $\left(\mathrm{kg} / \mathrm{m}^{3}\right)$ & 1500 & 1567 \\
\hline Specific gravity & 2.667 & 2.667 \\
\hline Fines \% (by weight) & 2 & 0.8 \\
\hline Water absorption $(\%)$ & - & 1.5
\end{tabular}

Silica fume (SF): Micro silica powder with silicon dioxide $\mathrm{SiO}_{2}$ content of $93.3 \%$, its chemical compositions from the XRF test are given in Table 3.

Table 3: Chemical Compositions of Silica Fume (SF) from the XRF Test

\begin{tabular}{lllllllllllll}
\hline \multicolumn{10}{c}{ Oxide Content (\%) } \\
\hline $\mathrm{SIO}_{2}$ & $\mathrm{ALO}_{3}$ & $\mathrm{FeO}_{3}$ & $\mathrm{CaO}$ & $\mathrm{MgO}$ & $\mathrm{SO}_{3}$ & $\mathrm{Na}_{2} \mathrm{O}$ & $\mathrm{K}_{2} \mathrm{O}$ & $\mathrm{P}_{2} \mathrm{O}_{5}$ & $\mathrm{Cl}$ & LOI & Total \\
\hline 93.3 & 0.34 & 0.09 & 0.58 & 1.07 & 0.86 & 0.12 & 0.39 & 0.07 & 0.03 & 3.11 & 99.96 \\
\hline
\end{tabular}

Corrugated segment steel fibers (CSSF): Steel corrugated wavy fibers of dimension $50 \pm 3$ mm length, $2 \pm 0.1 \mathrm{~mm}$ width, 0.4-0.6 mm thickness, 6-7 mm wave-length, and $2 \pm 0.2 \mathrm{~mm}$ wave heights, as shown in Fig. 2, were used. The corrugated segment steel fibers were made of low carbon drawn wire with a minimum tensile strength of $1200 \mathrm{MPa}$.

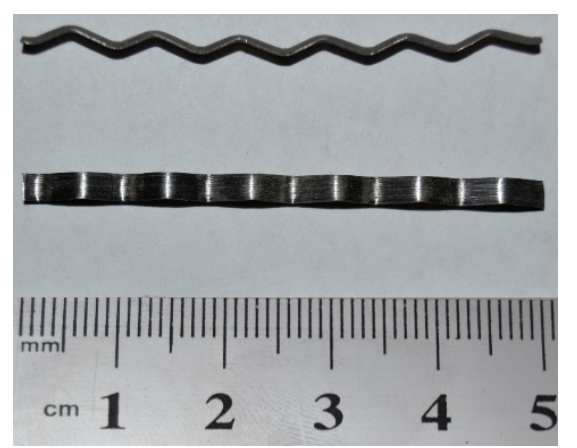

Fig. 2: Corrugated Segment steel Fibers

Super-plasticizer (SP): A highly effective dual action liquid super-plasticizer of 2-3\% of cement content were added for water-reduction and promoting high early and ultimate strengths, produced by sika (Sikament NN). 
Reinforcing steel bars: $10 \mathrm{~mm}$ diameter ribbed bar with minimum yield strength of 360 $\mathrm{MPa}$, minimum ultimate tensile strength of $520 \mathrm{MPa}$, and minimum elongation of $12 \%$. Produced according to Egyptian Standards (EOS 262, 2000) Grade 360/520.

\section{TESTED SPECIMENS}

\subsection{Concrete Core Material}

Three different mixes were used to achieve the aforementioned objectives. Total of nine $158 \times 158 \times 158 \mathrm{~mm}$ cubes for each mix were used to determine the concrete compressive strength after 7, 28, and 60 days of water curing, according to (BS EN 12390-3, 2009). The compressive strengths were determined based on the average of three results. In addition, total of nine prisms, measured $100 \mathrm{~mm}$ wide, $100 \mathrm{~mm}$ high, and $500 \mathrm{~mm}$ long, for each mix were used to determine the concrete flexural strength, according to (BS EN 12390-5, 2009), after 7, 28 , and 60 days of water curing. The flexure strengths were determined based on the average of three prisms results tested under four-point bending. Moreover, total of three $69 \pm 2 \mathrm{~mm}$ cubic specimens were used to determine the abrasion resistance according to (BS EN 1338, 2003 ) after 28 days of water curing. The abrasion resistance was determined from the average weight loss of three specimens subjected to Böhme abrasion wheel tester. Before the test, specimens were dried in an oven at $50{ }^{\circ} \mathrm{C}$ until reaching to constant weight.

\subsection{Covers Structure System}

A total of four covers steel frames measuring $770 \times 713 \mathrm{~mm}$ (length $\times$ width) with shear connectors were prepared. the shear connectors is to enhance the composite action between steel and concrete, and increase the load carrying capacity of the TE manhole covers (Yan et al., 2016). Fig. 3 shows the developed reinforcement configuration for the developed covers. The shear connectors' distribution and shapes were selected to provide maximum quantity with uniform distribution at the punching zone.

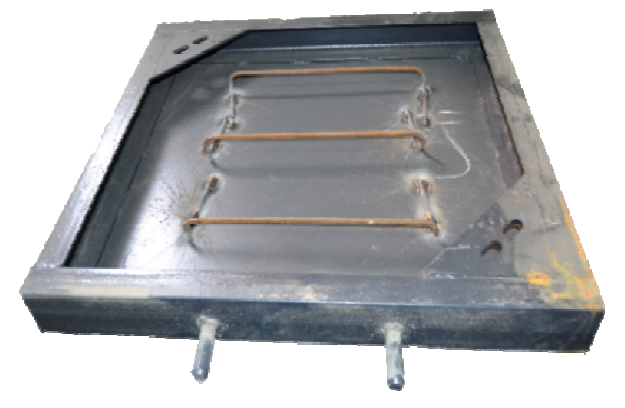

Fig.3: The reinforcement configuration for the developed covers

Covers (1), (2) were made using concrete mixture of M1-S0-F0 as control specimen covers specimens while Covers (3), (4) made using the developed mixture of M5-S10-F50 from Phase (I) as concrete core material. Fig. 4 shows the typical fabrication process and curing of the SC composite cover.
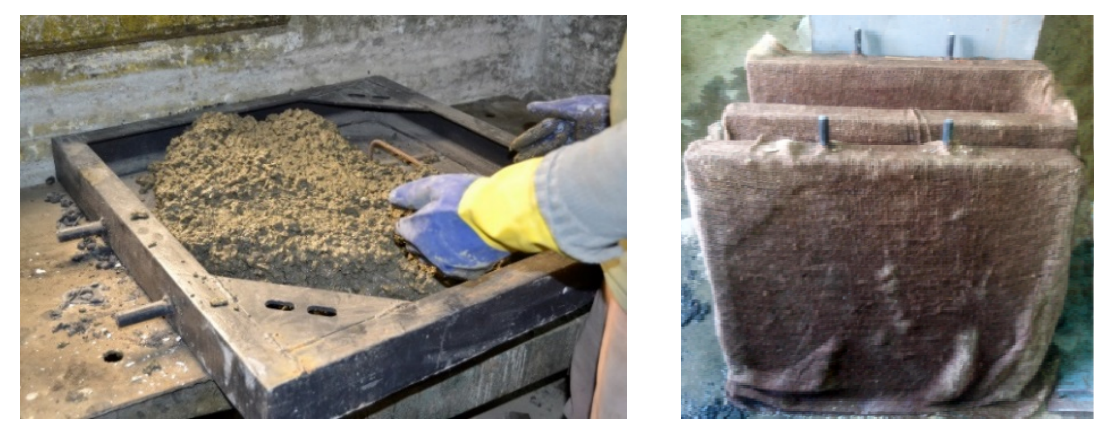

Fig. 4: Typical fabrication process and curing of the (SC) composite cover 


\section{TEST SETUP AND INSTRUMENTATIONS}

The flexure test was four-point bending test over a clear span of $300 \mathrm{~mm}$. The prisms had a clear shear span of $100 \mathrm{~mm}$, while the distance between the two loading points was $100 \mathrm{~mm}$ (constant moment zone). The mid-span deflection was measured using a dial gauge to obtain load-deflection curves. The test setup is shown in Fig. 5.

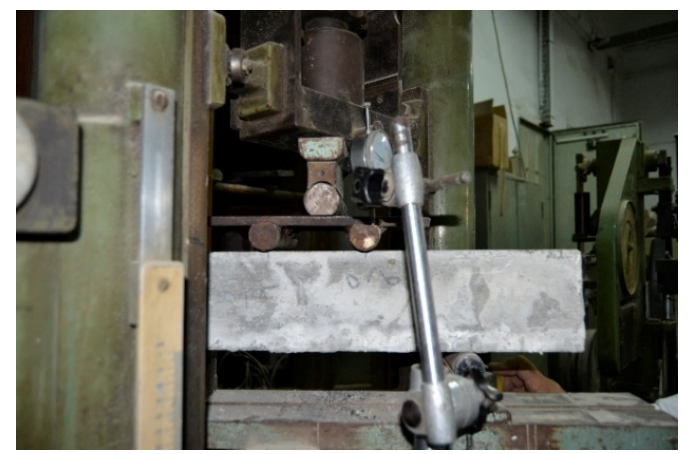

Fig. 5: Flexure test setup

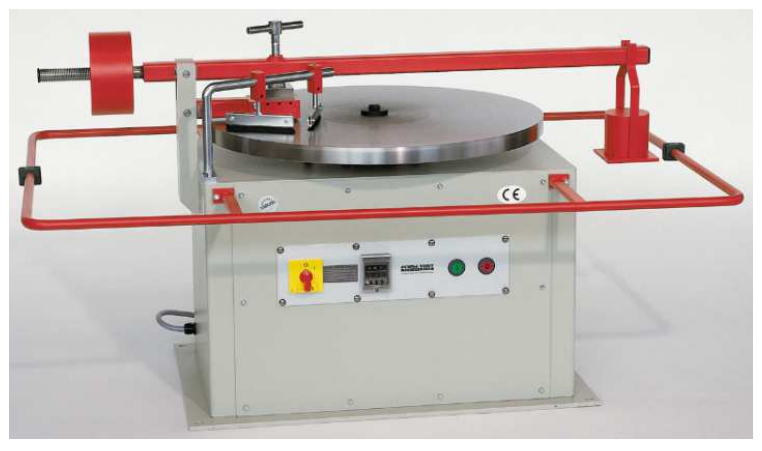

Fig. 6: Abrasion test setup

The abrasion resistance was determined with Böhme abrasion wheel tester. The test setup is shown in Fig. 6.

Fig. 7 shows the test setup for SC composite covers. Each cover was simply supported on four sides over rigid steel frame and placed on the bed of the test machine. The load was applied to the cover over a steel disk of $250 \mathrm{~mm}$ diameter and $45 \mathrm{~mm}$ thick. Rubber disk of 25 mm diameter was used between the steel disk and concrete cover to reduce the effect of stress concentration. The load was measured using $3000 \mathrm{kN}$ load cell.

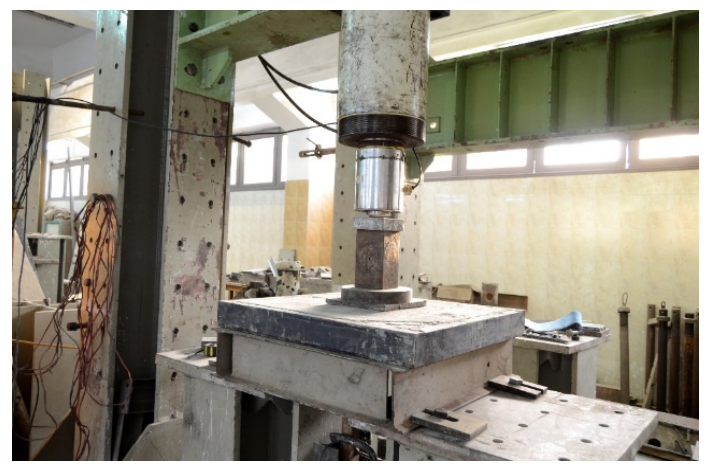

Fig. 7: Cover test setup

All deflection, and applied loads were recorded by the computer-controlled data logger during the test. The ultimate resistances and corresponding failure modes were observed and recorded through tracing the load versus deflection and load versus strain.

According to BS EN 124 (BS EN 124-1, 2015) the covers were loaded up to $2 / 3$ of the test load and then released. This was repeated five times then the permanent deflection measured. After that the cover loaded to the test load bearing capacity and held for thirty seconds without failure to be accepted. Finally, the load increased till cover failure and the ultimate resistance was the failure load.

\section{TEST RESULTS AND DISCUSSION}

6.1. Phase (I): This phase identifies the concrete properties of mixture specimens in presence of constant additional amount silica fume (10\% of cement content) and corrugated segment steel fiber $(50 \mathrm{~kg} / \mathrm{m} 3)$. 
Table 4. Shows the test results for different mixes.

Table 4. Shows the test results for different mixes

\begin{tabular}{ccccccccc}
\hline \multirow{2}{*}{ ID } & $\begin{array}{c}\text { Slump } \\
(\mathbf{m m})\end{array}$ & \multicolumn{2}{c}{$\boldsymbol{f}_{\boldsymbol{c u}}(\mathbf{M P a}) / \mathrm{Days}$} & \multicolumn{3}{c}{$\boldsymbol{f}_{\boldsymbol{t}}$ (MPa) } & \multirow{2}{*}{$\begin{array}{c}\text { Abrasion (\% of weight } \\
\text { loss) }\end{array}$} \\
\cline { 3 - 8 } & $\mathbf{7}$ & $\mathbf{2 8}$ & $\mathbf{6 0}$ & $\mathbf{7}$ & $\mathbf{2 8}$ & $\mathbf{6 0}$ & 1.44 \\
\hline M0-S0-F0 & 50 & 20.8 & 30.6 & 30.6 & 2.8 & 4.7 & 4.7 & 1.45 \\
\hline M1-S0-F0 & 30 & 31.0 & 38.0 & 38.4 & 3.5 & 5.6 & 6.0 & 0.69 \\
\hline M2-S10- F50 & 30 & 35.4 & 49.0 & 52.0 & 7 & 8.6 & 9.2 & \\
\hline
\end{tabular}

Abbreviation: M1: Refer to concrete mixture; the number refers to the mix number; S0: Refer to silica fume, the number refers to the percentage of silica fume added from cement content; F0: Refer to corrugated segment steel fibers, the number refers to the weight in $\mathrm{kg}$ of corrugated segment steel fibers added in cubic meter.

\subsubsection{Compressive strength}

As mentioned before, this research project includes two main specimens reference M0-S0F0, simulates the commercial manufactured concrete, and the control mix M1-S0-F0 that designed to have minimum voids ratio. The mix design has an obvious influence on the compressive strength at different ages. Where the concrete compressive strength of the control mixture M1-S0-F0 was increased by about $24 \%$ compared to the commercial mixture M0-S0F0. Mixture M2-S10-F50 that combine two additives (silica fume, and steel fibers) shows obvious influence in the compressive strength at both 28 and 60 days. The compressive strength increased by about $29 \%$ and $35 \%$ at 28 and 60 days of curing, respectively, compared to the compressive strength of control mix M1-S0-F0, and increased by about $60 \%$ and $70 \%$ at 28 and 60 days of curing, respectively, compared to the compressive strength of commercial mix M0-S0-F0. This enhancement in compressive strength mainly referred to the major effect of silica fume presence and neglecting the effect of steel fibers. The above remarks can be observed from the results shows in Table 4.

\subsubsection{Flexure strength and deflection}

The mix proportion has an obvious and significant effect on the flexure strength at different ages. Where the concrete flexure strength of the control mixture M1-S0-F0 was increased by about 19\% compared to the commercial mixture M0-S0-F0. Mixture M2-S10-F50 that combine two additives (silica fume, and steel fibers) has a remarkable influence in the flexure strength at both 28 and 60 days. The flexure strength increased by about $54 \%$ and $53 \%$ at 28 and 60 days of curing, respectively, compared to M1-S0-F0, and increased by about $83 \%$ and $96 \%$ at 28 and 60 days of curing, respectively, compared to M0-S0-F0. This progress and change in flexure strength is mainly due to the major accumulative effect of silica fume, and steel fibers presence together.

\subsubsection{Abrasion resistance}

According to Böhme abrasion wheel test results, the abrasion resistance (by weight loss $\% \mid$ ) of the commercial mix M0-S0-F0 and the control mix M1-S0-F0 is almost similar with no remarkable difference. However, M2-S10-F50 matrix that combines two additives (silica fume, steel fibers) showed a significant increasing in abrasion resistance compared to M0-S0F0 and M1-S0-F0 matrix. And has the greatest effect on abrasion resistance of all specimens. M2-S10-F50 matrix abrasion resistance increased by about $52 \%$ at 28 days of curing compared to the control mix M1-S0-F0. This clear improvement and enhancement in abrasion resistance mainly indicated and referred to the massive and clear effect of corrugated segment steel fibers and silica fume presence. 
6.2. Phase (II): This phase focused on the maximum load bearing capacity and, the covers behavior for the developed covers with the enhanced concrete from Phase (I).

\subsubsection{General Behaviors and Failure Modes}

All specimens were suddenly failed due to punching shear of the concrete core around the patch loads. The applied load versus deflection relationship offers a good way to describe SC composite covers behaviors for the tested covers as shown in Fig. 11.
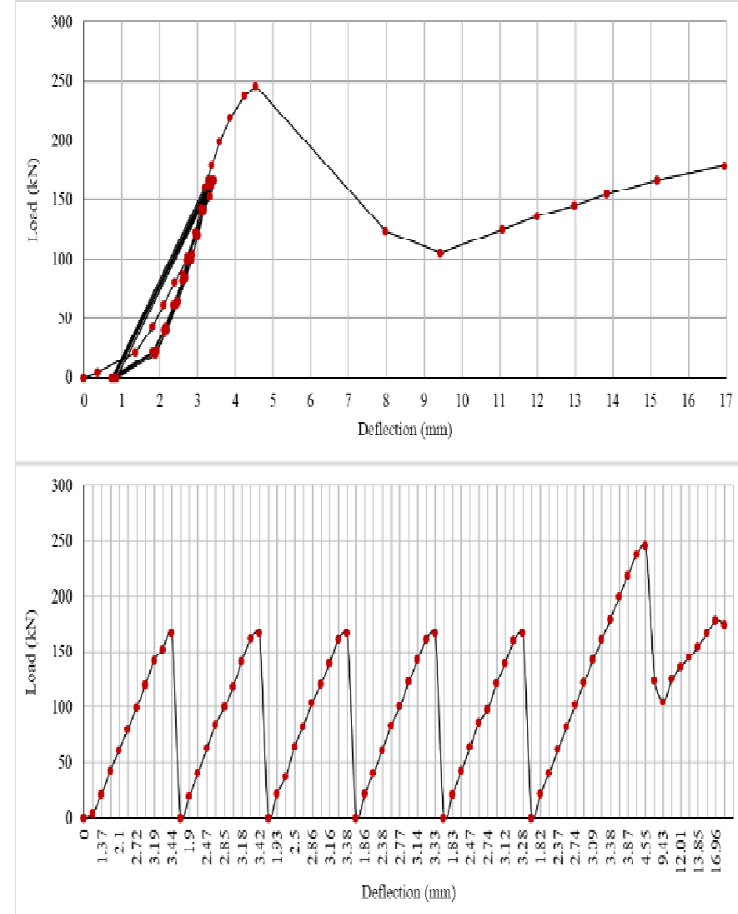

Cover $1,2 \quad(\mathrm{a}$
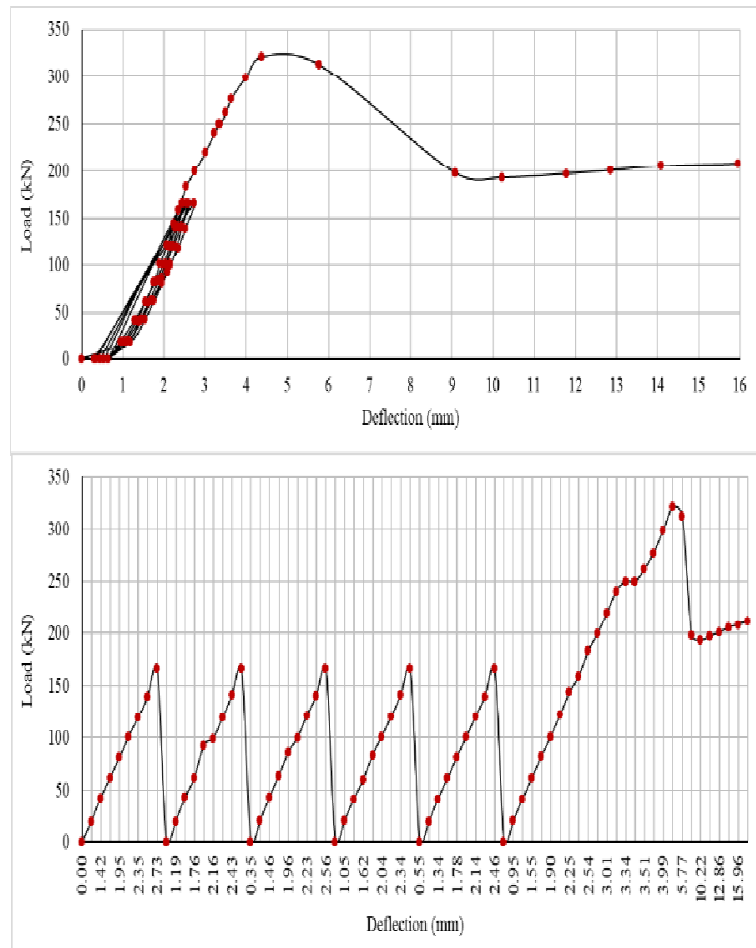

Cover $3,4 \quad(b$

Fig. 11: Load-deflection curves for tested covers

For all specimens, the critical punching shear perimeter was located away from the loading edge with an average distance of 0.7 the effective depth of the covers, as shown in Fig. 12. Moreover, the inclination angle of the punching cone surface was measured after failure and found in range of $35^{\circ}$ to $40^{\circ}$.

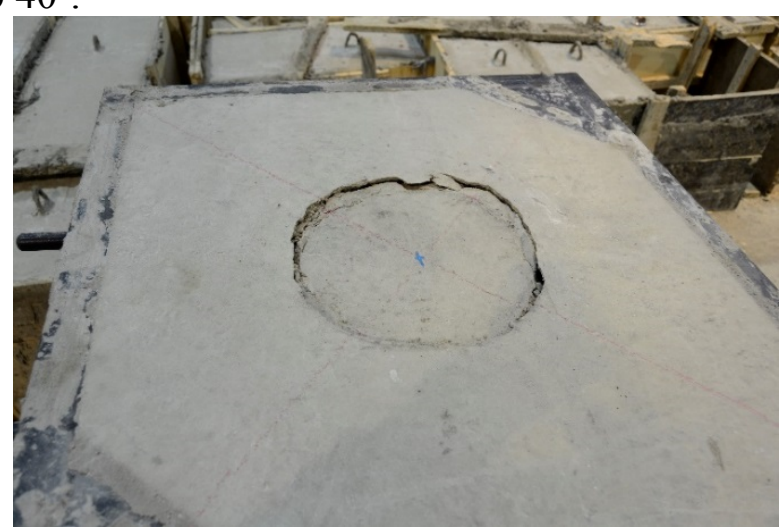

Fig. 12: Punching shear failure of the concrete core

\subsubsection{Ultimate Resistance}

BS EN 124 (BS EN 124-1, 2015) standards assigned the minimum load bearing capacity of the covers according to the installation place. Where, TE manhole covers were classified as 
groups 3 (Class C 250) in case of installation in the area of curbside of roads. According to BS EN 124 the minimum load bearing capacity for group 3 are $250 \mathrm{kN}$.

Table 5: The covers test results

\begin{tabular}{ccccccc}
\hline ID & Concrete Mix & Test class & $\begin{array}{c}\mathbf{2 / 3} \\
\text { Test load }\end{array}$ & Test load & Ultimate load & $\begin{array}{c}\text { Permanent } \\
\text { deflection }\end{array}$ \\
\cline { 1 - 2 } Cover 1,2 & M1-S0-C0-F0 & & & & 246 & 0.73 \\
\cline { 1 - 2 } Cover 3,4 & M2-S10-C4-F50 & & 166.7 & 250 & 322 & 0.65
\end{tabular}

Table 5 presented the ultimate resistances and the permanent deflection for each tested cover. While the permissible permanent deflections were driven according to (EN124 Clause 7.3) as follow:

Permissible permanent set $=\frac{\sigma_{0}}{\sigma_{0}}$

Where $c_{o}$ is the dimension of the cover short span

According to the equation, the maximum permanent deflection of the covers is $2.38 \mathrm{~mm}$. The permanent deflection of each specimen listed in Table 5.

The maximum load bearing capacity for covers $(1,2)$ is $246 \mathrm{kN}$ which is lower than the permissible bearing capacity of $250 \mathrm{kN}$ according to BS EN 124 for covers class C250. While the maximum load bearing capacity for covers $(3,4)$ is $322 \mathrm{kN}$ which is comply with BS EN 124 for the covers class C250. Therefore, both of shear connectors and the enhanced concrete have a significant effect on the bearing capacity that make the covers able to be installed safely in the area of curbside of roads.

\subsubsection{Effect of Concrete Strength}

As shown in Table 4, the mix design has an obvious influence on the compressive and flexure strength of concrete. Produced enhanced concrete mix M2-S10 -F50 increased the compressive strength by $29 \%$ and $35 \%$ after 28 and 60 days of curing, respectively, and increased the flexure strength by $54 \%$ and $53 \%$ after 28 and 60 days of curing, respectively, comparing with the control mix M1-S0-F0. This enhancement in compressive and flexure strength of concrete significantly increased ultimate punching capacity of covers $(3,4)$ by about $30 \%$ compared to the control specimen covers $(1,2)$. Moreover, increased the tensile resistance of the concrete leads to increase the connectors' pull-out and breakout force, which consequently increased the punching capacity.

\subsubsection{Effect of connectors quantity and Distribution}

The failure surface and perimeter of the punching cone as shown in Fig. 3 allows to determine the number of the intersected shear connectors with the punching core for covers. As the spacing of the connectors decreased, its quantity increased leading to higher bearing capacity. Increasing the connectors' quantity, firstly strengthen the composite action of the cover structure which increase the moment inertia of the cover cross section, and increase stiffness, leading to cracks width reduction as well as deflection reduction. Secondly, increasing number of shear dowels will increase the probability of bridging the punching cracks result in higher bearing capacity of covers.

\section{SUMMARY AND CONCLUSIONS}

This experimental study aims at enhancing the concrete properties and the structure system of telecommunications (TE) manhole covers in order to improve its durability, serviceability, increase safety factors and increase the cover ultimate bearing capacity. Based on the experimental results and the above discussions, the following conclusions can be derived:

1) A developed mix contain $10 \% \mathrm{SF}$, and $50 \mathrm{~kg} / \mathrm{m}^{3}$ CSSF enhancing the compressive strength by about $29 \%$ and $35 \%$ at 28 and 60 days, respectively compared to that of control mix. This enhancement in compressive strength mainly referred to the major effect of silica fume presence. 
2) Both of steel fibers and silica fume have a significant effect on the abrasion resistance. The abrasion resistance of the developed mix was enhanced by about $48 \%$ at 28 days of curing compared to control mix.

3) In this study, the main mode of failure for (SCC) covers under the patch loads can be classified as the punching shear suddenly failure of the concrete core.

4) The punching shear capacity is influenced by the strength of the concrete, the quantity and distribution of the connectors.

5) The commercial covers steel bars mesh serves no structural function because the (SCC) covers structure replaces the steel bars mesh by a steel bottom plate and the steel plate is more efficient in carrying biaxial stresses than a mesh of steel bars.

6) Both of shear connectors and the enhanced concrete have a significant effect on the cover bearing capacity that make the covers comply with BS EN 124 for the covers class C250, therefore the developed covers able to be installed safely in the area of curbside of roads.

\section{Acknowledgments}

The authors wish to acknowledge the support of the Material Research Center (MRC) and Concrete Labs in the Structural Engineering Department, Faculty of Engineering, Ain Shams University, Cairo, Egypt.

\section{REFERENCES}

1. British Standard Institution. (2003). BS EN 1338: Concrete Paving BlocksRequirements and test methods. In British Standards (Vol. 3, Issue 1, pp. 1-33).

2. British Standard Institution. (2009). BS EN 12390-5: Testing hardened concrete Part 5: Flexural strength of test specimens. British Standard, 3(1), 420-457.

3. British Standard Institution. (2015). BS EN 124-1: European standards for gully tops and manhole tops for vehicular and pedestrian users,British Standard(pp. 1-45).

4. British Standard Institution. (2009). BS EN 12390-3: Testing hardened concrete Part 3: Compressive strength of test specimens, , UK. In British Standard (Issue August, pp. 1-16).

5. Egyptian Organization for Standardization \& Quality. (2000). EOS 262: Steel For The Reinforcement of Concrete (pp. 1-16).

6. El Haggar, S., \& El Hatow, L. (2009). Reinforcement of thermoplastic rejects in the production of manhole covers. Journal of Cleaner Production, 17(4), 440-446.

7. Nili, M., \& Afroughsabet, V. (2012). Property assessment of steel-fibre reinforced concrete made with silica fume. Construction and Building Materials, 28(1), 664-669.

8. Telecom Egypt company. (2019). Telecom Egypt Financial Information. http://ir.te.eg/en/FinancialInformation/FinancialStatements

9. Egyptian Organization for Standardization \& Quality. (2008). EOS 4207: the Egyptian standard for gully tops and manhole tops for vehicular and pedestrian users (pp. 1-32).

10. Yan, J. B., Wang, J. Y., Liew, J. Y. R., Qian, X., \& Li, Z. X. (2016). Punching shear behavior of steel-concrete-steel sandwich composite plate under patch loads. Journal of Constructional Steel Research, 121, 50-64. 